\title{
Probabilistic Reasoning For Improving THE Predictive Maintenance of Vital Electrical Machine: CASE StUdy
}

\author{
Abdelaziz LAKEHAL ${ }^{1, *}$, Ahmed RAMDANE ${ }^{2}$, Fouad TACHI ${ }^{3}$ \\ ${ }^{1}$ Department of Mechanical Engineering, Mohamed Chérif Messaadia University, P.O. Box 1553, \\ Souk-Ahras, 41000, Algeria \\ ${ }^{2}$ Department of Mechanical Engineering, Faculty of Technology, University of 20 August 1955, \\ Skikda, Algeria \\ ${ }^{3}$ Algerian Petroleum Institute, School of Skikda, Algeria \\ *Corresponding Author: Abdelaziz LAKEHAL (email: lakehal21@yahoo.fr) \\ (Received: 27-October-2017; accepted: 17-January-2018; published: 31-March-2018) \\ DOI: http://dx.doi.org/10.25073/jaec.201821.74
}

\begin{abstract}
Nowadays, new information technologies produce new methodological approaches attempting to extract not just valid and reliable information, but more generally a particular technical and professional expertise to support the decision making. A Bayesian network was developed for fault assessment of an electrical motor. By inference, this model made it possible to calculate the probability of rotor fault of the induction motor, while defining the weakest branch in the structure of the Bayesian network that leads to failure by determining the probabilities of intermediate events. The most likely faults were then defined and the information system consolidated, as well as the decision-making process. The article ends with an application that shows the methodology developed and gives some results illustrated by figures.
\end{abstract}

\section{Keywords}

Predictive maintenance; Bayesian network; induction motor; Rotor fault prediction; information.

\section{Introduction}

Induction motors are widely used (it is estimated that $80 \%$ of the motors used in the various industrial domains in the world are of the induction motor type) because their cost is lower than that of other machines. Moreover these motors are robust. The power range covered by induction motors is very wide, ranging from 5 watts, for single-phase induction motors, to $36.8 \mathrm{MW}$, for squirrel-cage motors. They are of variable criticality. In practice, some motors are classified as vital, others as important, and others as unimportant.

Preventive maintenance is commonly associated with high power motors. Nowadays, and given the importance of these machines and the economic losses that their shutdown generates, a conceptual evolution is necessary. We need to move from preventive maintenance to predictive maintenance. Predictive maintenance ensures that the machine will be kept in good condition, extends its life cycle and, above all, improves its availability. The implementation of a predictive maintenance strategy requires a rigorous analysis of the motors, the modes of degradation, the electrical and mechanical parameters, the means 
to be used, and the objectives in terms of availability.

In order to ensure a good mastery over time of the predictive maintenance of induction motors, the maintenance plan must contain all the necessary information. The exploitation of the history files and the experience gained through the exploitation of the information held by the experts give a good contribution. The masterpiece of the approach set out in this article is the inventory of failures, in logic of causality, while linking causes to effects. The next phase is the definition of the priorities in terms of intervention. In this case, the fundamental objective is to establish the planning of the interventions which allows representing, in a global and synthetic way, the activity of the predictive maintenance on these motors.

With the required high productivity levels at industrial plants, any urgent corrective maintenance action or unscheduled shutdown can cause significant economic losses. In industries like petrochemical, some techniques, as vibration analysis, are able to detect the fault's early onset which could avoid more serious problems. In this sense, there are many studies focused on early fault detection. In complementarities, in recent years several artificial intelligence techniques have been developed and applied in the monitoring processes of faults, among them, the Fuzzy Logic, Artificial Neural Networks, and Support Vector Machines [1, 2, 3].

An efficient supervised Artificial Neural Network (ANN) learning technique that is able to identify fault type when situation of diagnosis is uncertain was presented by [4. Significant features are taken out from the electric current which are based on the different frequency points and associated amplitude values with fault type.

Bayesian networks are also artificial intelligence tools little used for fault prediction in electrical machines [5]. A new fault diagnosis method for rotating machinery based on adaptive statistic test filter and Diagnostic Bayesian Network is presented by [6]. A three-layer diagnostic Bayesian network is developed to identify condition of rotation machinery based on the Bayesian theory. In another contribution, a Bayesian network of motor fault diagnosis model based on stator current signal and its Hilbert marginal spectrum feature was introduced [7]. The results found have shown that this fault diagnosis model is effective and accurate.

In this paper, a Bayesian model will be developed to build an information system that can predict failures in induction motors. The Bayesian formalism presented in this work gives a strong contribution to the prioritization of maintenance actions and the planning of preventive maintenance work.

\section{Bayesian network tool}

Basically, a Bayesian network represents a graphic transposition of knowledge. The two main elements constituting a Bayesian network are: its structure and its parameters. The structure of this type of network is simple: a graph in which the nodes, representing random variables, and the edge (so the graph is oriented), connecting these nodes, are connected to conditional probabilities. Note that the graph is acyclic, i.e. it does not contain a loop. Edges represent relationships between variables that are either deterministic or probabilistic. Thus, the observation of one or more causes does not systematically result in the effect or effects that depend on it, but only modifies the probability of observing them.

The particular interest of Bayesian networks is to take into account simultaneously the a priori knowledge of experts (on the graph) and the experience contained in the data. The graphical representation of a Bayesian network is explicit, intuitive and comprehensible by a nonspecialist, which facilitates both the validation of the model, its possible evolutions and especially its use. 


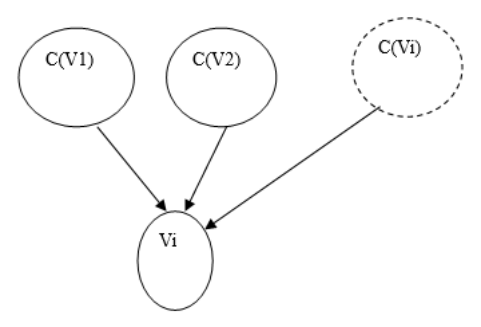

Fig. 1: Bayesian network.

The parameters of the Bayesian network are the a priori probabilities, for the input variables, and the a posteriori probabilities, for the output variables of the model. The computation of the a posteriori probabilities is done by inference in the Bayesian network based on the Bayes theorem (see formula 1). It describes the probability of an event, based on prior knowledge of conditions that might be related to the event.

Depending on the type of application, the practical use of a Bayesian network can be considered in the same way as other models: neural networks, expert systems, decision trees, data analysis models, tree failures, logic models, etc. a BN (Fig. 1) is defined by a directed acyclic graph (DAG) as:

$$
p\left(V_{1}, V_{2}, \ldots, V_{n}\right)=\prod_{i=1}^{n} p\left(V_{i} / C\left(V_{i}\right)\right)
$$

Where $C\left(V_{i}\right)$ is the set of parents (or causes) of $v_{i}$ in the graph (Fig. 1).

In recent last years, Bayesian networks have been widely used in the field of diagnosis and prediction [8, 9]. The central element of any Bayesian approach is information. Complete or incomplete, these tools find solutions for reasoning under uncertainty. They are also powerful decision support tools widely used in the modeling of complex and dynamic systems [10].

\section{Bayesian network development}

A Bayesian network was constructed from peer-reviewed technical literature, census data, and fault statistics reports. When required probability data were unavailable or the sample size was too small, an expert in maintenance engineering provided subjective estimates of the probabilities.

\subsection{Construction of the model structure}

In any case, in fault analysis the effect is a feared event, whose causes we attempt to identify. Tab. 1 presents basic and intermediate events causing faults in the rotor of induction motor. Also in the same Table a codification is adopted, each code representing a variable in the BN developed in the rest of this article. The causal relationship determines the structure of the network. A research in the literature made it possible to define the parents of each node in a global way then a questionnaire addressed to the operators made it possible to give details on the causes and the affects and the relations between them.

Tab. 1: Census of causes causing rotor faults.

\begin{tabular}{|c|c|c|c|}
\hline $\begin{array}{l}\text { Faulty } \\
\text { ele- } \\
\text { ment }\end{array}$ & Fault nature & Causes & Code \\
\hline \multirow{19}{*}{$\begin{array}{l}\text { Rotor } \\
\text { faults }\end{array}$} & & & 1 \\
\hline & Bearing fault & & 11 \\
\hline & & $\begin{array}{l}\text { Magnetic imbal- } \\
\text { ance }\end{array}$ & 111 \\
\hline & & Loss of lubricant & 112 \\
\hline & & High temperature & 113 \\
\hline & & Unbalanced load & 114 \\
\hline & $\begin{array}{l}\text { Breaking } \\
\text { bars }\end{array}$ & & 12 \\
\hline & & $\begin{array}{l}\text { Magnetic imbal- } \\
\text { ance }\end{array}$ & 111 \\
\hline & & $\begin{array}{ll}\text { Long } & \text { transient } \\
\text { regime } & \end{array}$ & 121 \\
\hline & & Thermal fatigue & 122 \\
\hline & $\begin{array}{l}\text { Magnetic cir- } \\
\text { cuit fault }\end{array}$ & & 13 \\
\hline & & Thermal fatigue & 122 \\
\hline & & Overload & 132 \\
\hline & $\begin{array}{l}\text { Bearing mis- } \\
\text { alignment }\end{array}$ & & 14 \\
\hline & & Coupling error & 141 \\
\hline & & Overload & 132 \\
\hline & & $\begin{array}{l}\text { Excessive gap in } \\
\text { the bearings }\end{array}$ & 142 \\
\hline & $\begin{array}{l}\text { Rotor mis- } \\
\text { alignment }\end{array}$ & & 15 \\
\hline & & $\begin{array}{ll}\text { Magnetic imbal- } \\
\text { ance }\end{array}$ & 111 \\
\hline
\end{tabular}




\begin{tabular}{|l|l|l|c|}
\hline & & Bearing fault & 11 \\
\hline & $\begin{array}{l}\text { Mechanical } \\
\text { imbalance }\end{array}$ & & 16 \\
\hline & & $\begin{array}{l}\text { Movement of short- } \\
\text { circuit rings }\end{array}$ & 161 \\
\hline & & Alignment problem & 14 \\
\hline
\end{tabular}

For a cage rotor, the faults are limited to the breaking of rods or the breakage of short-circuit rings.

Thus, for the purpose of a detailed presentation faults are classified. The most intuitive graphical representation of the influence of an event, a fact, or a variable on another is to represent causality by linking the cause to the effect by an oriented edge. The structure of the BNs, developed in this paper, focuses on the causality principle which is the basis of Bayesian reasoning. Identified faults are thus illustrated in the $\mathrm{BN}$ given in Fig. 2.

A global analysis of the fault causes organized on a single induction motor is carried out. After grouping relevant and meaningful information by categories (cause and effect), and presenting cause-and-effect links (after confirmation of the fault) with edges. Such a network allows a complete and visual operation, relatively easy, of each induction motor.

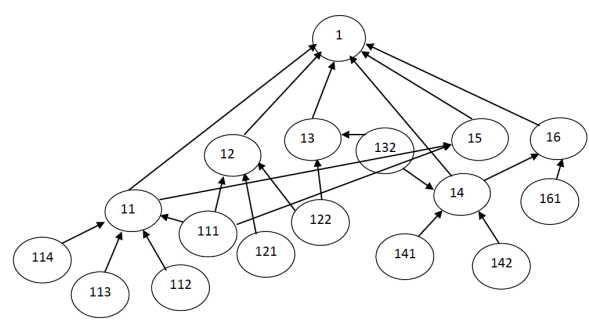

Fig. 2: Graphical Bayesian model for predicting the rotor faults.

\subsection{Definition of model parameters}

The parameters of the Bayesian network are: the a priori probabilities and the a posteriori probabilities. The a priori probabilities are defined based on the history of machine failures. Basically, they are the electrical measurements and the various conditional maintenance tech- niques that can determine the existence of these faults. The a priori probabilities represent the probabilities of occurrence for each type of failure.

The a posteriori probabilities will be calculated by inference in the Bayesian network. The tables of the conditional probabilities define the causality links between the variables, and then by applying the formula (1) we find the a posteriori probabilities. The definition of the network parameters must performed with a special attention, because the results depend intimately on data. The model input data and the consequent results are among the most important elements of a Bayesian approach. They are evidence of the feasibility of corrective actions and the appropriateness of decisions, and are the basis for answering the questions and corroborating the assumptions of failure scenarios. It is therefore crucial to present them in a precise and honest way, so that their interpretation is simple and understandable even by a non-specialist (a manager for example).

\section{Application and discussion}

In order to improve the availability of the induction motor, we might have to establish a motor failure model that represents the rotor's faults as an effect function of some input variables (causes). Having done that, prediction of a rotor fault could be accomplished by calculating a posteriori probabilities.

For example, when considering the availability of an induction motor, as we do in this paper, the controllable variables can be the electrical measurements, vibration, and the number of spare parts of different types.

To validate the proposed methodology an important induction motor used in SONATRACH / SKIKDA / GL1K / LNG plant is assigned as the study motor with a power of $288 \mathrm{~kW}$. The installations of the motor were started up in 2000.

The information for defining the probability of fault will be evaluated only on the basis of experience feedback and the history file of the ma- 
chine. While the structure of the network will be defined by an expert, in view of its complexity of definition, in this case the role of the operator is primordial. Referring to the history file of the studied induction motor, the results of the conducted diagnostics, it's possible to define the a priori probabilities for each cause (Tab. 3). Information concerning Thermal fatigue fault does not exist in the historical data, an estimate of an expert can regularize the a priori probability.

Tab. 2: A priori probabilities.

\begin{tabular}{|c|c|c|}
\hline Causes & Code & $\begin{array}{c}\text { A priori } \\
\text { probabilities }\end{array}$ \\
\hline $\begin{array}{c}\text { Magnetic } \\
\text { imbalance }\end{array}$ & 111 & 0.089 \\
\hline $\begin{array}{c}\text { Loss of } \\
\text { lubricant }\end{array}$ & 112 & 0.297 \\
\hline $\begin{array}{c}\text { High } \\
\text { temperature }\end{array}$ & 113 & 0.124 \\
\hline $\begin{array}{c}\text { Unbalanced } \\
\text { load }\end{array}$ & 114 & 0.265 \\
\hline $\begin{array}{c}\text { Long } \\
\text { transient } \\
\text { regime }\end{array}$ & 121 & 0.001 \\
\hline $\begin{array}{c}\text { Thermal } \\
\text { fatigue }\end{array}$ & 122 & 0.042 \\
\hline $\begin{array}{c}\text { Overload } \\
\text { Coupling } \\
\text { error }\end{array}$ & 132 & 0.095 \\
\hline $\begin{array}{c}\text { Excessive } \\
\text { gap in } \\
\text { the bearings }\end{array}$ & 142 & 0.110 \\
\hline $\begin{array}{c}\text { Movement of } \\
\text { short-circuit } \\
\text { rings }\end{array}$ & 161 & 0.099 \\
\hline
\end{tabular}

The conditional probability table (CPT) defines the causality links in the Bayesian formalism given in Section 3. For example, Tab. 4 shows a conditional probability table for fault 14:

Tab. 3: Conditional probability table for fault 11 .

\begin{tabular}{|c|c|c|c|c|c|c|c|c|c|}
\hline & 132 & \multicolumn{4}{|c|}{ True } & \multicolumn{4}{c|}{ False } \\
\hline & 141 & \multicolumn{2}{|c|}{ True } & \multicolumn{2}{c|}{ False } & \multicolumn{2}{|c|}{ True } & \multicolumn{2}{c|}{ False } \\
\hline & 142 & True & False & True & False & True & False & True & False \\
\hline & True & 1 & 1 & 1 & 1 & 1 & 1 & 1 & 0 \\
\hline 14 & False & 0 & 0 & 0 & 0 & 0 & 0 & 0 & 1 \\
\hline
\end{tabular}

The inference rules are given by the conditional probability table. Some readings are as follows:

- If the cause 132 takes the state True then the fault 14 exists.

- If the cause 141 takes the false state and the cause 132 takes the false state then the fault 14 exists if and only if the cause 142 takes the state True.

- If the causes 132,141 , and 142 take the state false, there is no fault in the rotor.

In the Bayesian formulations, as soon as the number of variables becomes important, computations become complicated. To relax these constraints a program was written in Matlab environment. After inference in the network of Fig. 2 the a posteriori probabilities for each fault can be found, as well as for the rotor fault (Tab. 4).

From the results given in Tab. 4 it is possible to make decisions on the corrective actions that should be carried out in a certain environment. Also these prediction results give the possibility to organize the actions in a specific order of priority. It is to be noticed that the probability of having a fault in the rotor $(73.70 \%)$ is significant, and the main faults in decreasing order are respectively: Bearing fault and rotor misalignment, mechanical imbalance, bearing misalignment, magnetic circuit fault, breaking bars.

The Bayesian network of Fig. 2 is causal network. From a practical point of view, to connect causality with Bayes' theorem, the joint law of a cause $C(V i)$ and its consequence $V i$ is represented by the factorization $P(C(V i) \cdot P(V i \mid C(V i))$. To show that the graph of Fig. 2 satisfies the Markov condition, the calculation of the probability of node 13 with two 
states (true and false) is taken as an example:

$$
\begin{aligned}
& P(13=T)=P(13=T / 122=T, 132=T) \\
& \times P(122=T) \times P(132=T) \\
& +P(13=T / 122=T, 132=F) \times P(122=T) \\
& \times P(132=F)+P(13=T / 122=F, 132=T) \\
& \times P(122=F) \times P(132=T) \\
& +P(13=T / 122=F, 132=F) \\
& \times P(122=F) \times P(132=F) \\
& =(1 \times 0.042 \times 0.095)+(1 \times 0.042 \times 0.905) \\
& +(1 \times 0.958 \times 0.095)+(0 \times 0.958 \times 0.905) \\
& =0.00399+0.03801+0.09101 \\
& =0.13301
\end{aligned}
$$

In the same way it is possible to check the node $11,12,14,15,16$ and finally the node 1 .

Tab. 4: A Posteriori Probabilities.

\begin{tabular}{|c|c|c|c|}
\hline $\begin{array}{c}\text { Faulty } \\
\text { element }\end{array}$ & $\begin{array}{c}\text { Nature of } \\
\text { fault }\end{array}$ & Code & $\begin{array}{c}\text { A } \\
\text { posteriori } \\
\text { probability }\end{array}$ \\
\hline Rotor & $\begin{array}{c}\text { Bearing } \\
\text { fault }\end{array}$ & 11 & 0.73709297 \\
\hline & $\begin{array}{c}\text { Breaking } \\
\text { bars }\end{array}$ & 12 & 0.12813474 \\
\hline & $\begin{array}{c}\text { Magnetic } \\
\text { circuit } \\
\text { fault }\end{array}$ & 13 & 0.13301 \\
\hline & $\begin{array}{c}\text { Bearing } \\
\text { misalignment }\end{array}$ & 14 & 0.2605969 \\
\hline & $\begin{array}{c}\text { Rotor } \\
\text { misalignment }\end{array}$ & 15 & 0.58765081 \\
\hline & $\begin{array}{c}\text { Mechanical } \\
\text { imbalance }\end{array}$ & 16 & 0.33379781 \\
\hline
\end{tabular}

Vibration analysis and current signature analysis are widely used for fault diagnosis in electric motors. In the case where several faults appear simultaneously, the fault diagnosis becomes difficult with the vibration analysis technique. A Rotor misalignment fault and Magnetic circuit fault can occur at the same moment and with neighboring frequencies $(100 \mathrm{~Hz}$ for 3000 rot/min). Also, a poorly calibrated sensor may give false alarm. The current signature analysis is sensitive to load variations and supply oscillations. However, the reliability of these precursors is not sufficient to identify the pos- sible fault. The same go with temperature, partial discharge, gas analysis, surge test, magnetic flux, the air-gap torque, and power. All these methods diagnostic a single fault. In this situation the exploitation of the information held by the operators remains the only way to make decisions on the faults prediction. The Bayesian network developed in this study gives the probability of occurrence of fault on the basis of the behavior of the machine and with very precise values which makes it possible to take decisions in all certainty.

In the network of Fig. 2 some information modifies the beliefs that we have on the machine. In this Bayesian network the notion of probability used is a subjective notion of belief. Results of Tab. 4 measure the belief that a cause attributes to the occurrence of a given fault. Operators operate a vital induction motor even with alarming vibration levels. On the other hand face a strong probability that the rotor breaks down $(73 \%)$ the operator does not take the risk. One reason for attributing a stronger belief to one fault rather than another is given by the a posteriori probabilities. These results give the possibility to anticipate the faults; this also saves time earlier wasted in responding to false alarms, and consequently makes reliable the prediction.

It should be mentioned that the structure of the model remains the same for all induction electrical machines. But the network parameters (a priori probabilities) change from one machine to another.

The basis for prioritizing the maintenance actions of motor for each fault is the Bayesian network of Fig. 2, Tab. 4 shows the a posteriori probabilities of the basic failures in the rotor of motor which were obtained by inference in the Bayesian network. The impact of the bearing fault of all faults is jointly seen in the results for the predictive maintenance plan of the studied motor. Considering the values given by Tab. 4 , the prioritizing failure within the framework of the predictive maintenance is: Bearing fault and rotor misalignment, mechanical imbalance, bearing misalignment, all faults are mechanical. It is seen that in the final scenario the failures that have a higher priority should be corrected first. Also, the prioritization depends 
on the motor and the operating conditions, as shown in Fig. 2.

In this study, fault assessment is stated in terms of probabilities. Also the proposed Bayesian network is simple and intuitive. By comparing it by other tools (expert system, neural network) it can be used by a non-specialist. Now, to practically proof the effectiveness of the proposed work, it is necessary to eliminate the causes that have high priority and to re-evaluate again the availability rate of the motor.

The proposed tool is a systematic tool for decision making in the field of diagnostic and prediction of faults, formalizing the interpretation of information and measurement results, and in particular the recurrent logical links that can be made, has the significant advantage of facilitating the work of the expert, or even of replacing it in simple or classic cases of diagnosis / prediction. Indeed, discharged from a systematic work that he realizes each time, the expert can focus then on higher-level work.

\section{Advantages of the bayesian network tool over other artificial intelligence techniques}

In the Bayesian formulation used in this paper the belief calculation amount for each fault candidate is small regarding to others techniques such as: artificial neural networks (ANN), Fuzzy logic, Expert systems. The second common advantage of Bayesian network regarding the artificial intelligence techniques listed above is that the graphic representation of a Bayesian network is simple, intuitive and understandable by a nonspecialist. it should be noted that the artificial intelligence tools listed above are more suitable and more efficient for online fault detection in induction motor compared to the Bayesian networks, but do not give a justified and precise information on the forecast occurrence of the fault.

Two types of ANNs have given a strong contribution in diagnostic and prediction of faults in induction motors: supervised and unsuper- vised ANNs. Unsupervised ANNs do not need to train before, and their training is carried out online continuously. However, implementation of ANN based method needs a spacious practical data of the motor in different operating conditions. Also, change of the motor working conditions in different environments may affect the fault detection, and the trained ANN for each motor is unique [11. Also expert knowledge cannot be previously represented in the ANN. By contrast, in the Bayesian network the structure represents knowledge and the relationships between the variables and the parameters of the network can be updated easily. The learning ability is moderate regarding Bayesian network. The ANN not allow a very large work amount in the fault prediction, their performance is small, while the Bayesian networks are very efficient on this.

The calculations of the probability distribution associated with a Bayesian network are falls within the inference. For the methods based on fuzzy logic technique the accuracy of predicting results is bad in deep inference regarding with Bayesian networks tools which is excellent in error tolerance and in deep inference. Also, if the domain experience representation is good for the induction motor fault prediction based on fuzzy logic, it is moderate relatively to Bayesian network in the learning ability. The wide range of size and power of induction motors that can be covered by prediction methods based on Bayesian networks and those based on fuzzy logic remains a common advantage.

In the Bayesian networks, the predicting models are universal to the all power range of motors, but methods based on expert systems may not have sufficient accuracy in detecting and predicting the fault in small motors. Bayesian networks can cover new states in its database, it is only necessary to update its conditional probability table. But, the main drawback of an expert system is that it cannot cover new states in its database, because the database is defined in a limited area [11. Also, with the Bayesian networks the developing of work amount is very large compared with Expert system which is moderate. In the Bayesian networks the inference and learning algorithms are complicated. 


\section{Conclusions}

Through this paper an application of the Bayesian networks was presented. The modeling of the knowledge held by the experts and the exploitation of the history file have allowed the definition of a Bayesian network for the prediction of failures in an induction motor. The article shows that it is possible to define priorities for maintenance actions. Only the rotor part of the motor was presented, but it is possible to model the stator part in the same way. However, the article shows that the majority of causes of unavailability of the studied machine are of mechanical origin. From the figures obtained, it is possible to prepare the resources and plan the actions.

Once this modeling is generalized on all the machines of an industrial site, it is possible to establish a predictive maintenance plan as well as an action plan for the operating site. The developed Bayesian model is standard for all asynchronous machines; we just need to update the a priori probabilities of the model to make it appropriate. The model developed represents a decision-making tool that justifies actions by precise numbers.

\begin{tabular}{l}
\hline \multicolumn{3}{|c|}{ ACKNOWLEDGEMENT } \\
The authors are thankful to the \\
SONATRACH / SKIKDA / GL1K / LNG \\
plant for providing necessary infrastructural \\
facilities for caring out the research work. \\
Also they would like to express their appre- \\
ciations for the anonymous reviewers for the \\
very constructive comments that have helped \\
greatly improve their manuscript.
\end{tabular}

\section{References}

[1] AYDIN, I., M. KARAKOSE, E. AKIN, "A new real-time fuzzy logic based diagnosis of stator faults for inverter-fed induction motor under low speeds," Proceedings of 14th International Conference on Industrial Informatics (INDIN), pp. 446-451, 2016.

[2] BAZAN, G.H., P.R. SCALASSARA, W.E.A. GOEDTEL, W.F. GODOY,
R.H.C. PALÁCIOS, "Stator fault analysis of three-phase induction motors using information measures and artificial neural networks," Electric Power Systems Research, vol. 143, pp. 347-356, February 2017.

[3] MUSTAFA, M.O., D. VARAGNOLO, G. NIKOLAKOPOULOS, T. GUSTAFSSON, "Detecting broken rotor bars in induction motors with model-based support vector classifiers," Control Engineering Practice, vol. 52, pp. 15-23, July 2016.

[4] ALTAF, S., M.W. SOOMRO, M.S. MEHMOOD, "Fault Diagnosis and Detection in Industrial Motor Network Environment Using Knowledge-Level Modelling Technique," Modelling and Simulation in Engineering, vol. 2017, 10 pages, 2017.

[5] GONG, Y-SHAN., Y. LI, "Motor Fault Diagnosis Based on Decision Tree-Bayesian Network Model," Advances in ECWAC, vol. 1, AISC 148, pp. 165-170. Springer-Verlag Berlin Heidelberg, 2012.

[6] LI, K., Q. ZHANG, K. WANG, P. CHEN, H. WANG, "Intelligent Condition Diagnosis Method Based on Adaptive Statistic Test Filter and Diagnostic Bayesian Network," Sensors, vol. 16, pp. 76, 2016.

[7] ZHAO, Y.N., F. LIN, T. JIN, "Application of Bayesian network based on cuckoo algorithm in fault diagnosis of asynchronous machine," Journal of Mechanical \& Electrical Engineering, vol. 02, 2016.

[8] LAKEHAL, A., F. TACHI, "Bayesian Duval Triangle Method for Fault Prediction and Assessment of Oil Immersed Transformers," Measurement and Control, vol. 50, no.4, pp. 103-109, 2017.

[9] LAKEHAL, A., F. TACHI, H. CHEGHIB, "A new contribution for fault prediction of electrical power transformers", Proceedingsof 6th International Conference on Systems and Control (ICSC), pp. 372-376, 2017. 
[10] LAKEHAL, A., Z. GHEMARI, "Availability Assessment of Electric Power based on Switch Reliability Modelling with Dynamic Bayesian Networks: Case Study of Electrical Distribution Networks," Journal of Mathematics and System Science, vol. 7, no. 5, pp. 289-295, 2015.

[11] OJAGHI, M., M. SABOURI, J. FAIZ, "Diagnosis methods for stator winding faults in three-phase squirrel-cage induction motors," International Transactions on Electrical Energy Systems, vol. 24, no. 6, pp. 891-912, 2014.

\section{About Authors}

Abdelaziz Lakehal received the Engineer degree in Industrial Maintenance, the Magister degree in Mechanical Engineering, the $\mathrm{PhD}$ degree, and the Habilitation to conduct researches in Electromechanical Engineering, in 2004, 2007, 2013, and 2016 respectively. From 04/2012 to 10/2014, he was appointed as Lecturer in the National Higher School of Technology, Algiers. In 2014, he moved to Mohamed-Chérif Messaadia University, Souk-Ahras, Algeria, where he is currently Senior Lecturer. His research interests include maintenance, quality reliability and safety, sensors, fault diagnosis and prediction. On the application side he is mainly interested in the field of maintenance engineering.

Ahmed RAMDANE received the Engineer degree in Electromechanical Engineering, and the Magister degree in Electromechanical Engineering, in 2004, and 2007 respectively. He is currently a Ph.D student at University of 20 August 1955, Skikda, Algeria. His research is focused on the fault diagnosis and prediction using artificial intelligence methods.

Fouad TACHI received his State Engineer degree in Automatic Control from the Department of Electrical Engineering, University of Badji Mokhtar, Annaba, Algeria, and the MSc. in Control Systems Engineering from the Department of Automatic Control and Systems Engineering, University of Sheffield, Sheffield, U.K., in 1990 and 2004, respectively. He then moved to Algerian Petroleum Institute, School of Skikda, Algeria, where he is currently Lecturer - Researcher in Control Engineering. His research interests are in the field of systems modeling and identification, optimization, Distributed Control, intelligent systems, and systems failure diagnosis.

"This is an Open Access article distributed under the terms of the Creative Commons Attribution License, which permits unrestricted use, distribution, and reproduction in any medium, provided the original work is properly cited (CC BY 4.0)." 